\title{
PRELIMINARY ANALYSIS OF IMAGE PROCESSING-BASED EVALUATION OF EMBOSSING QUALITY
}

\author{
Magdolna Pál (D), Bojan Banjanin (D), Sandra Dedijer (D), \\ Gojko Vladić (D), Gordana Bošnjaković (D) \\ University of Novi Sad, Faculty of Technical Sciences, \\ Department of Graphic Engineering and Design, Novi Sad, Serbia
}

\begin{abstract}
The embossing process in graphic industry utilizes custom made dies to create raised or lowered permanent relief patterns according to the design. It can be combined with other print finishing embellishments, such as foil stamping or pearlescent coating, but the simplest version of this process, the blind embossing is also a very effective technique to create a distinguished and sophisticated look. The quality control of embossing features was done only visually for a long time, but in the recent years it became an important target for graphic instrument manufacturers focusing on the embossing depth, as one of the most important parameters for high quality processing. This analysis was aiming to investigate the applicability of a simple flatbed scanner and the developed image processing algorithm for embossing quality evaluation. The results of detailed visual assessment of all scanned paper samples and the obtained values of average greyscale difference (shadow-based contrast), showed that single-level embossed samples can be realistically digitalized using a simple flatbed scanner, as an image acquisition equipment. Additionally, the proposed image feature, the shadow-based contrast had increasing tendency by increasing the applied compression force, in general, suggesting that it has a potential as an objective measure for the deformation rate in the embossing quality evaluation. The obtained results gathered for different combinations of observed parameters (paper grade, basis weight, type of test elements on the embossing dies) with the optimal compression forces, implied that the shadow-based contrast could be used as a reference parameter to ensure adequate visibility of embossed elements by defining the minimum value of needed contrast.
\end{abstract}

Key words: embossing, blind embossing, quality control, image processing

\section{INTRODUCTION}

During the embossing process, paper fibres are reshaped into well-defined permanent relief patterns, usually by using heat and force. The design can be raised or lowered, depending on which type of techniques and dies are employed. If the relief is raised, it is defined as positive or embossed, but if the relief is lowered, it is negative and commonly called debossed. In both cases, usually two dies are employed: an impressed (concave) female die and a matching male die. The embossed image itself could have flat or sculpted design. In accordance, they are obtained by a single-level or multi-level die, respectively (Blechschmidt, 2013; Holik, 2013; Topac, 2016; Terril, 2019; FSEA, 2020). Although, the embossing process can be used as stand-alone operation, there are numerous combinations using different type of foils, inks, varnishes, holograms, etc. Blind embossing, as the simplest technique among them, creates a visible image without colour or foil. The visual sensation and legibility are coming from the shadows created by incident light hitting the edges of the recessed or raised elements on the embossed surface. The greater the relief, the more emphasized the shadow, clearer the visibility. In some cases, the applied pressure and heat can change the original texture and colour of the substrate, so the design could be visible through them too. Theoretically, any types of paper and paperboard can be embossed, but there are some recommendations regarding to the substrates' properties, such as material thickness, composition, fibre nature and length, surfaces and overall strength properties (tensile strength, elongation, toughness tearing resistance, delamination strength, compression strength and especially bursting strength). If the substrate is thick, dense and strong, the embossed image will hold better, with more details, complicated patterns, pronounced relief and embossed depth. At the other hand, bulky substrates will respond in a spongier way, since they are more compressible that other paper grades, but also recycled paper and paperboard will require significantly higher pressure compared to virgin fiber stock due to the high compression levels of recycled fibres. Howsoever, embossing as a reshaping process will reach its limits where surface damages appear on the substrates (Topac, 2016; Storaenso, 2019; Terril, 2019; FSEA, 2020; Iggesund, 2020). Another limitation of the embossing application is the design element's dimensions. Illustration with small details 
and fine lines cannot be embossed as deeply as larger areas, since these fine details are prone to rupture the substrate. In contrast, larger elements have to be embossed more deeply to create a proper tactile effect (Peret, 2020), but high-quality embossing is not just all about depth. There are physical limitations to how much a paper can stretch, therefore creating a pronounced texture with fine detail is often more important than getting a lot of depth (SAPPI, 2020).

Beside the substrates, dies are the other critical element for achieving the desired embossed image. Different metals are suitable to manufacture embossing dies by etching or engraving, but nowadays as new approaches, 3D printed and laser-engraved dies were utilized successfully in proof of concept setups or in trial runs. Copper, magnesium, brass and steel are the conventional materials for embossing dies, manufactured by etching and engraving. The material and producing technique are determined by the run length, complexity of the design and the desired longevity of the dies (Iggesund, 2020; FSEA, 2020; SAPPI, 2020).

Although, it is a traditional print finishing technique used for high-quality and luxury printed products, its quality control was done only visually for a long time (Iggesund, 2020; FSEA, 2020). In the recent years with the development of different machine or computer-based control systems, the quality control of embossing features was becoming an important target for graphic instrument manufacturers (Peret, 2019; Inspectron, 2020; Peret, 2020; Starrett, 2020). As one of the most important parameters for high quality processing, the embossing depth was in their focus. Low embossing depth would not result in adequate visual and tactile effects on the substrates, but also, too deep embossing would cause problems in the form of ruptures, cracks, wrinkles and other surface damages. These commercially available instruments are fine-tuned, optimized for fast and accurate quality control in real manufacturing environment, however, they could represent an expensive investment for small businesses, design studios, craft workshops, etc. A simple and more affordable computer-aided visual assessment of embossing quality could be a good alternative, but also it would be a great help for 3D printed or laser-engraved dies development. For that purpose, a detailed investigation was performed to analyse the applicability of a simple flatbed scanner and an image processing algorithm for embossing quality evaluation. This study is focusing on the embossing pressure analysis, based on the difference between the average grayscale levels of areas under and outside shadows on the previously scanned embossed substrates.

\section{MATERIALS AND METHODS}

In order to ensure a wide variety in thickness, structure and surface characteristics of the embossing substrates, commercially available coated, uncoated and bulk papers with different basis weights were chosen for this investigation. The values of basic properties of selected papers and the corresponding standards are presented in Table 1 (Fedrigoni, 2020; Mondigroup, 2020).

Table 1: Basic properties and corresponding standards of selected papers

\begin{tabular}{|c|c|c|c|c|}
\hline $\begin{array}{l}\text { Group } \\
\text { number }\end{array}$ & Paper grade & $\begin{array}{l}\text { Basis weight } \\
{\left[\mathrm{g} / \mathrm{m}^{2}\right]} \\
\text { ISO } 536\end{array}$ & $\begin{array}{l}\text { Thickness } \\
{[\mu \mathrm{m}]} \\
\text { ISO } 534\end{array}$ & $\begin{array}{l}\text { Roughness } \\
\text { (Bendsten) } \\
\text { [m/lmin] } \\
\text { ISO 8791-2 }\end{array}$ \\
\hline 1. & \multirow{4}{*}{$\begin{array}{l}\text { Coated } \\
\text { (Fedrigoni Symbol } \\
\text { Freelife Satin) }\end{array}$} & $130 \pm 3.9$ & $160 \pm$ & $20 \pm 10$ \\
\hline 2. & & $150 \pm 4.5$ & $180 \pm$ & $20 \pm 10$ \\
\hline 3. & & $170 \pm 5.1$ & $200 \pm$ & $20 \pm 10$ \\
\hline 4. & & $200 \pm 8.0$ & $230 \pm$ & $20 \pm 10$ \\
\hline 5. & \multirow{5}{*}{$\begin{array}{l}\text { Uncoated } \\
\text { (Mondi MAESTRO } \\
\text { PRINT) }\end{array}$} & $80 \pm 3.0$ & $105 \pm 4.0$ & $225 \pm 75$ \\
\hline 6. & & $100 \pm 4.0$ & $126 \pm 5.0$ & $225 \pm 75$ \\
\hline 7. & & $120 \pm 4.5$ & $144 \pm 6.0$ & $225 \pm 75$ \\
\hline 8. & & $140 \pm 5.5$ & $164 \pm 6.0$ & $225 \pm 75$ \\
\hline 9. & & $170 \pm 7.0$ & $198 \pm 7.0$ & $225 \pm 75$ \\
\hline 10. & \multirow{3}{*}{$\begin{array}{l}\text { Bulk } \\
\text { (Hellefos Snowbulk } \\
70 \text { ISO) }\end{array}$} & $60 \pm 3.9$ & $120 \pm 3.0$ & - \\
\hline 11. & & $70 \pm 3.9$ & $140 \pm 3.0$ & - \\
\hline 12. & & $80 \pm 3.9$ & $160 \pm 3.0$ & - \\
\hline
\end{tabular}

For easier handling during the embossing process, the paper samples were cut into $350 \mathrm{~mm}$ long and 70 $\mathrm{mm}$ wide stripes using a high-speed cutting machine (Perfecta 72 HTVC). Two paper stripes were prepared 
for each paper grade, basis weight and embossing tool combinations (one for the compression force testing serial and one for the optimal force repeatability test).

In order to get into the limitation of different typographic and graphic elements as a base for the situations from real production process, four customised test forms were prepared based on previous investigations (Bošnjaković et al, 2017; Žarko et al, 2017, Banjanin et al, 2018) and corresponding industrial recommendations (Topac, 2016; Peret, 2019; FSEA, 2020; SAPPI, 2020). The test forms consisted of four sans-serif, technical letters (X, T, A and O) and different basic geometric elements (squares, circles, hexagons, octagon, triangles with different inner angles, lines with different thicknesses, rounded and flat ends) mostly in positive and at least in 3 different sizes (Figure 1). The embossing tools were prepared as single-level pair of two matching parts, a die and a counter die. Depending on the test forms' elements, usually the upper die was a female part, with the design etched into it, while the counter die was a male part with the corresponding raised design. Although, two different tool manufacturing methods were employed for the complete investigation, a conventional method of metal etching and a 3D printing method, for the purpose of this study, only the conventional tools were used and analysed. The embossing test tools were made of commercially available magnesium plates for embossing dies (Red Top, Magnesium Electron). Technical details of the die production process are shown in Table 2, while Figure $1 a$ and $b$ presents the developed test forms and the prepared embossing die sets, respectively.

Table 2: Technical details of the die production process

\begin{tabular}{|c|c|c|}
\hline $\begin{array}{l}\text { Process } \\
\text { step }\end{array}$ & $\begin{array}{l}\text { Production } \\
\text { process }\end{array}$ & Details, equipment and chemicals \\
\hline 1. & Film preparing & $\begin{array}{l}\text { Heidelberg Ultre } 5400 \text { Laser Imagesetter; light source: visible red laser diode with } \\
\text { emission wavelength of } 670 \mathrm{~nm} \text {; imaging principle: rotation monogon, maximum } \\
\text { screen frequency up to } 2001 \mathrm{pi} \text { at } 3386 \mathrm{dpi}\end{array}$ \\
\hline 2. & Exposure & $\begin{array}{l}\text { Duplomat Rectoplan; imaging principle: flatbed; light sources: one mercury bulb } \\
\text { with } 400 \mathrm{~W} \text {, four LED bulb with } 300 \mathrm{~W} \text {, one point light bulb with } 100 \mathrm{~W} \text {; exposure } \\
\text { time: } 15 \mathrm{~min}\end{array}$ \\
\hline 3. & Developing & $\begin{array}{l}\text { in basic container with solution of trichlorethylene } \mathrm{C}_{2} \mathrm{HCl}_{3} \text { (p.a. >99\%), developing } \\
\text { time: } 10 \mathrm{~min} \text { with an additional } 5 \mathrm{~min} \text { for drying }\end{array}$ \\
\hline 4. & Etching & $\begin{array}{l}\text { custom made frame, corrosive agent consists of nitric acid (HNO3), water and } \\
\text { mineral corrosive oil REV-FLEX Etch Additive, etching time: } 20 \mathrm{~min}\end{array}$ \\
\hline 5. & Stripping & With clean tap water \\
\hline
\end{tabular}
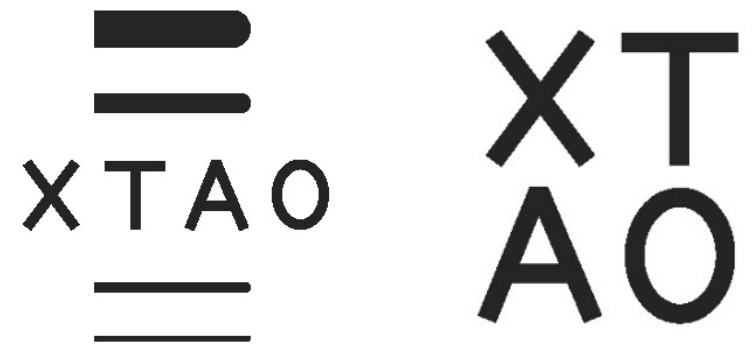

a)

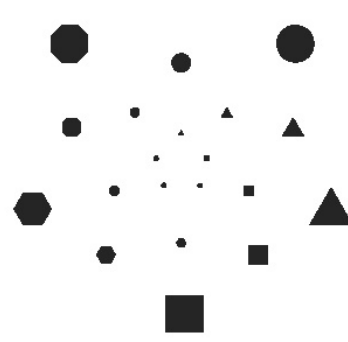

c) b)

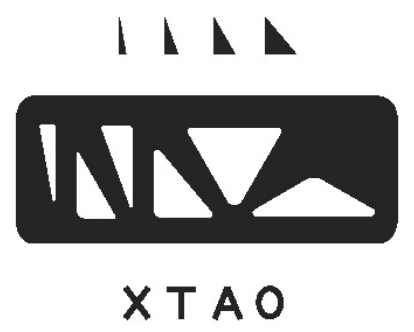

d)

Figure 1: The developed test forms: line elements and medium letters - die no. 1 (a), large letters - die no. 2 (b), smallscale geometric elements - die no. 3 (c), various triangles with small letters - die no. 4 (d) 
The embossing process was performed on a table top, single column, electromechanical universal testing machine Shimadzu EZ-LX (Shimadzu, Japan) using a high-precision load cell (capacity of 2500N, ISO 376 accuracy class 00), a fixed lower and a movable upper compression plates with radius of $118 \mathrm{~mm}$. The testing parameters were monitored and controlled by TRAPEZIUM X software (version 1.4.2, Shimadzu, Japan) in Single test mode and compression test type (Shimadzu, 2012). The speed of traction displacement, sampling frequency and compression time were constant for all paper samples $(2 \mathrm{~mm} / \mathrm{min}$, $10 \mathrm{~ms}$ and $2 \mathrm{~s}$, respectively), while the compression force has been varied for each paper sample individually and set up as a break detection threshold.

In order to determine the highest compression force (which would provide the highest possible contrast but without any damages, crispy edges, uneven or insufficient embossed depth), it was applied in gradually increasing manner with at least five different force values. Once paper sample reached its maximum deformability and the embossed surface was starting showing some damages, the embossing serial was stopped and the previous compression force was determined as the optimal force value. For the repeatability testing, five embossed samples were prepared with the optimal compression forces for each paper grade, basis weight and embossing tool combinations. All the embossing procedures were conducted in a controlled environment (at room temperature and standard relative air humidity) and the samples were conditioned for more than 48 hours prior to testing. The embossing process, its evaluation and the optimal compression force selection was performed by an expert on the spot, while the evaluation of embossing uniformity and repeatability were subsequently characterized by a digital image analysis method, described in the following section.

For the purpose of digital image analysis, all the embossed paper samples needed to be scanned first. The previously prepared samples have been digitized with a flatbed scanner (Canon CanoScan 5600F) at resolutions of 1200 spi, in grayscale mode without any advanced image settings of luminance and contrast. The dimensions of scanned area were $45 \times 45 \mathrm{~mm}$ and the images were saved as TIFF files with colour depth of 8 bit (Canon, 2020). In this manner 480 sample images were collected (12 different paper samples 4 embossing dies, 5 different compression force + the selected optimum force $x 5$ for each paperdie combination).

To obtain objective measure of compression force for adequate embossing quality, an image processing algorithm has been developed. It is based on the idea that embossed surfaces of different substrates such as paper, cardboard, polymer, metal, can be realistically digitalized by simple flatbed scanning (at higher resolution). During the scanning process, the scanner's built-in lamp evenly illuminates the complete embossed surface, but on the edges of recessed or raised elements, it creates shadows and the embossed image in digital form could be perceived similarly like in real viewing conditions. Moreover, the areas under shadows captured in that way could be analyzed by digital image processing. This represents a great potential, since in real viewing conditions, shadows as a phenomenon, cannot be really used in that way. The initial hypothesis of the developed algorithm for digital image processing lies on the difference between the average grayscale levels of areas under and outside shadows. That greyscale value difference, referred further as shadow-based contrast, hypothetically will rise with the applied pressure/force, since the higher compression forces will generate greater deformation on the paper, i.e. the recessed or raised elements of embossed images will be more emphasized. These emphasized elements will lead to greater distance between the original (non-embossed) surface and the processed (recessed or raised) surface which will result in darker shade of grayscale level of areas under shadows, therefore higher value of shadow-based contrast (higher value of average grayscale level difference). Additionally, the shadow-based contrast could be used as a reference value to ensure adequate visibility of embossed elements by defining the minimum value of needed contrast. Based on the described hypotheses and the analogy with the specific tasks for image processing presented in (Drobchenko et al, 2011; Malek, 2014; Nashat et al, 2014; Sinha, 2014; Goncalves et al, 2015), the developed algorithm includes the following image-processing steps: image segmentation (binarization), masking of the two regions of interest (ROIs): areas under shadows and the regularly illuminated areas, determination of average greyscale level for those two ROls and calculation of the difference between them. The simplified illustration of described method is shown in Figure 2. 

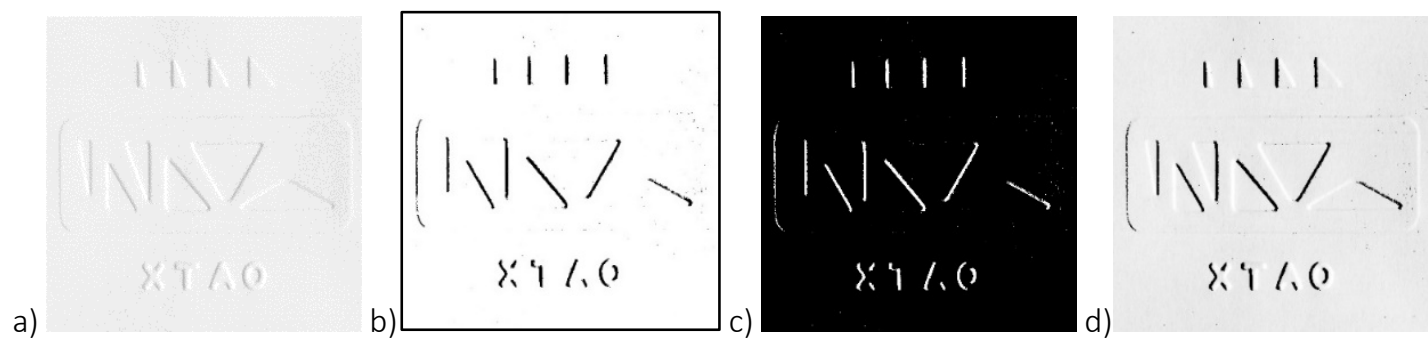

Figure 2: The shadow-masking procedure: original scanned image (a), segmented image (b), generated mask image (c) and selected areas under shadows (d)

First, the original grayscale image (Figure 2a) was converted to binary (Figure 2b) via image segmentation. For images with significant unimodal histogram, which is the current case as well, different thresholding methods were identified as suitable: three general-purpose thresholding methods (Kittler's, Otsu's and Kapur's) and two specific methods for unimodal histograms (Tsai's and Rosin's). After a detailed visual assessment of the original images and the corresponding segmented ones, Kapur's algorithm has been selected for the given task, since it can provide a well-balanced segmentation, without large-scale over or under-detection of fine details. As a result of segmentation, all the areas under shadows were replaced with black pixels, while all other areas were converted to white pixels. Therefore, the original binary image was suitable for masking the shadow areas and calculating the average grayscale level outside the shadows (Figure $2 \mathrm{~d}$ ), and vice versa, the negative binary image (Figure $2 \mathrm{c}$ ) was used for the average greyscale level calculus of surfaces under the shadows. The algorithm for image processing and average greyscale difference calculus was developed using software package MATLAB ${ }^{\circ}$ R2011a with the corresponding Image Processing Toolbox ${ }^{\mathrm{TM}}$.

\section{RESULTS AND DISCUSSION}

Results are presented and discussed in two phases. In the first, the applicability of the selected image attribute, the greyscale level of the areas under shadows and the proposed image feature, the shadowbased contrast, have been analysed in the function of realistic digital representation of embossed samples and an objective measure for the deformation rate in the embossing quality evaluation, respectively. In the second phase, the obtained results of shadow-based contrast were analysed regarding to the different paper grade, basis weight and type of test elements on the embossing dies.

Figure 3 shows the typical transition of grayscale levels from lighter to darker on scanned images due to increased compression force of the embossing process (coated paper with basis weight of $170 \mathrm{~g} / \mathrm{m}^{2}$ embossed with die no. 1). As it can be noticed, the lowest compression force of $600 \mathrm{~N}$ left a very light/mild/pale shadow (Figure 3a). The compression force of $800 \mathrm{~N}$ made a more apparent shadow (Figure $3 b)$, while the highest applied force, in this case $1000 \mathrm{~N}$, resulted in the most dominant shadow formation (Figure 3c). Similar tendencies could be noticed on the uncoated (Figure 4) and bulk (Figure 5) paper samples, regardless of the used die type. Additionally, the presented images clearly prove/demonstrate that embossed samples were realistically digitalized, therefore it is possible to use a simple flatbed scanner, as an image acquisition equipment for embossed paper samples, at least for the single-level embossed images.

a)

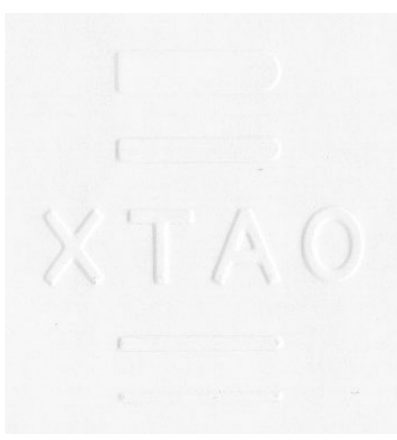

b)

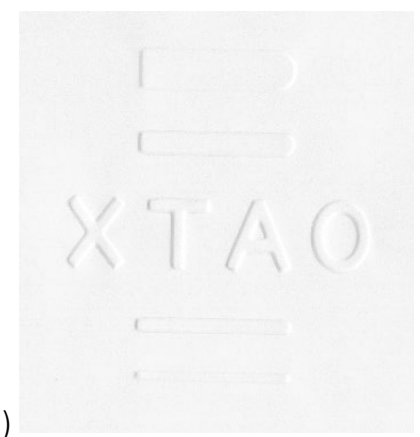

C)

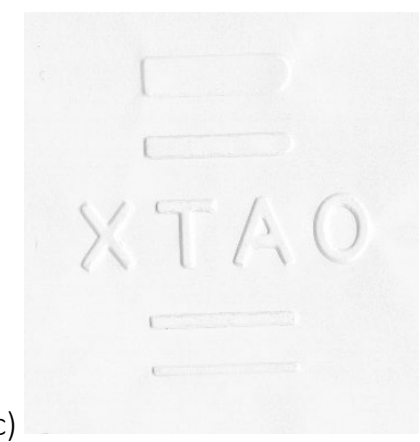

Figure 3: Samples of $170 \mathrm{~g} / \mathrm{m}^{2}$ coated paper embossed with $600 \mathrm{~N}(\mathrm{a}), 800 \mathrm{~N}(\mathrm{~b})$ and $1000 \mathrm{~N}(\mathrm{c})$ 
a)

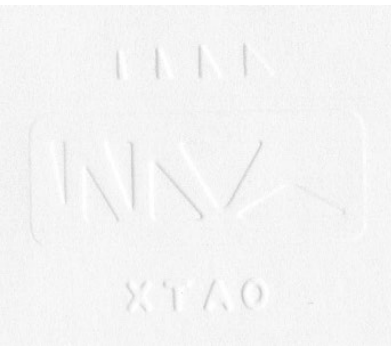

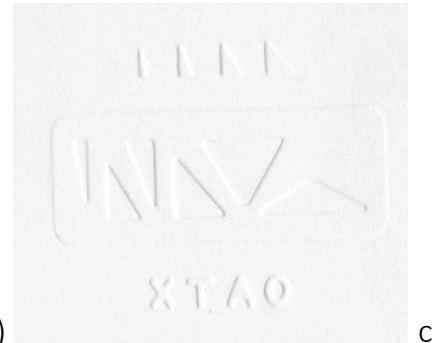

c)

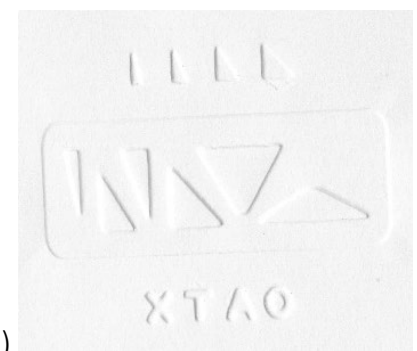

Figure 4: Samples of $120 \mathrm{~g} / \mathrm{m}^{2}$ uncoated paper embossed with $800 \mathrm{~N}(\mathrm{a}), 1000 \mathrm{~N}(\mathrm{~b})$ and $1200 \mathrm{~N}(\mathrm{c})$

a)

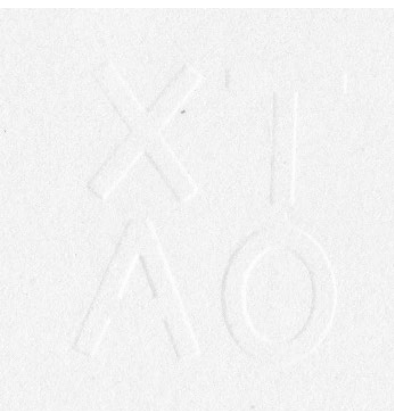

b)

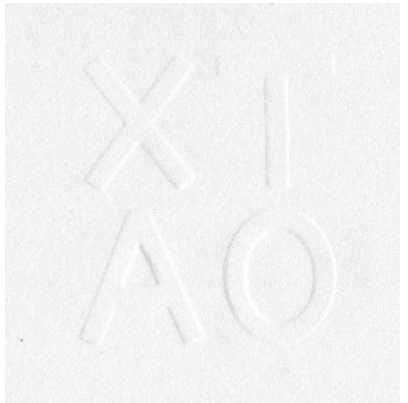

Figure 5: Samples of $80 \mathrm{~g} / \mathrm{m}^{2}$ bulk paper embossed with $325 \mathrm{~N}(\mathrm{a}), 375 \mathrm{~N}(\mathrm{~b})$ and $400 \mathrm{~N}(\mathrm{c})$

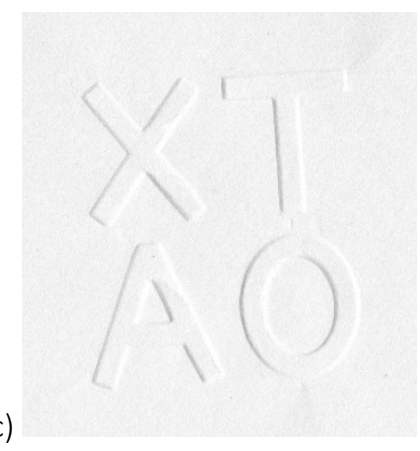

c)

The obtained results of average greyscale difference for the analysed sample papers embossed with different compression forces were grouped by the used die type and they are presented in Figure 6.

As it can be noticed, the values of average greyscale difference (i.e. shadow-based contrast) show increasing tendency by increasing the applied compression force in most of the observed paper and die combinations. Deviations could be noticed for bulk papers in the combination with all embossing dies, and for embossing die type 3 used almost on any type of paper sample. The corresponding values of coefficients of determination for uncoated and coated papers in the combinations of embossing die type 1, 2 and 4 were very high, ranging from $R^{2}=0.6079$ to $R^{2}=0.9971$, while bulk paper and embossing die no. 3 resulted in lower values, from $R^{2}=0.3420$ to $R^{2}=0.8502$ and from $R^{2}=0.2351$ to $R^{2}=0.8802$, respectively.

These low values of coefficients of determination for bulk paper can be associated with the structural and surface characteristics of these examined papers. Namely, they have a porous and spongy structure, with lower surface and overall strength due to a significant filler reduction and absence of surface sizing or coating. They usually exhibit poor deformability with significant tendency to creasing, cracking and tearing. During the embossing process they often randomly cracked or creased along the embossed elements even with a small or no compression force increase. These surface damages later on led to significantly darker patches on the scanned images and to the corresponding higher value of shadow-based contrast. Similarly, numerous surface cracks and/or creases were observed on almost every paper sample embossed with die type 3. The small-scaled geometric elements on the embossing die punched through the paper at higher compression forces instead of embossing it and generated dark spots on the scanned images. In the light of the fact that these damages were actually expected for bulk papers and also for the small, needle-like embossing elements, the low values of coefficients of determination for those samples are reasonable.

As it was mentioned before, this part of the experiment was dedicated to optimal compression force determination trough applying successively increasing compression forces until damages occurred on the embossed sample. When they occurred, the previous compression force, highest one which could provide the largest embossing deformation but without any damages, was determined as the optimal force value. Usually, all the embossed sample papers got more or less defined crease lines/wrinkles or cracks at the highest scheduled compression force, which were resulting in darker shade of greyscale value and higher shadow-based contrast.

By analysing the results regarding to the shadow-based contrast for these step-like force increments, the obtained greyscale difference values could be grouped into two major groups. The first one contains values of shadow-based contrast for lower compression forces and they are typically from 20 to 30 or slightly above. The second group includes greyscale difference values around 50, sometimes even 60, delivered by higher compression forces, which could potentially generate some damages on the samples and therefore 
a higher difference between the grayscale levels of the initial and the shadow-covered areas, too. This pattern suggests that damages on the embossed samples could be recognized not just visually, but also based on the difference in shadow-based contrast for successively increasing compression forces. In addition, since the presented results are indicating strong correlation between the shadow-based contrast value and the applied compression force, it is possible to track changes in the values of shadow-based contrast in accordance to the applied compression force, therefore the initial hypothesis was correct.

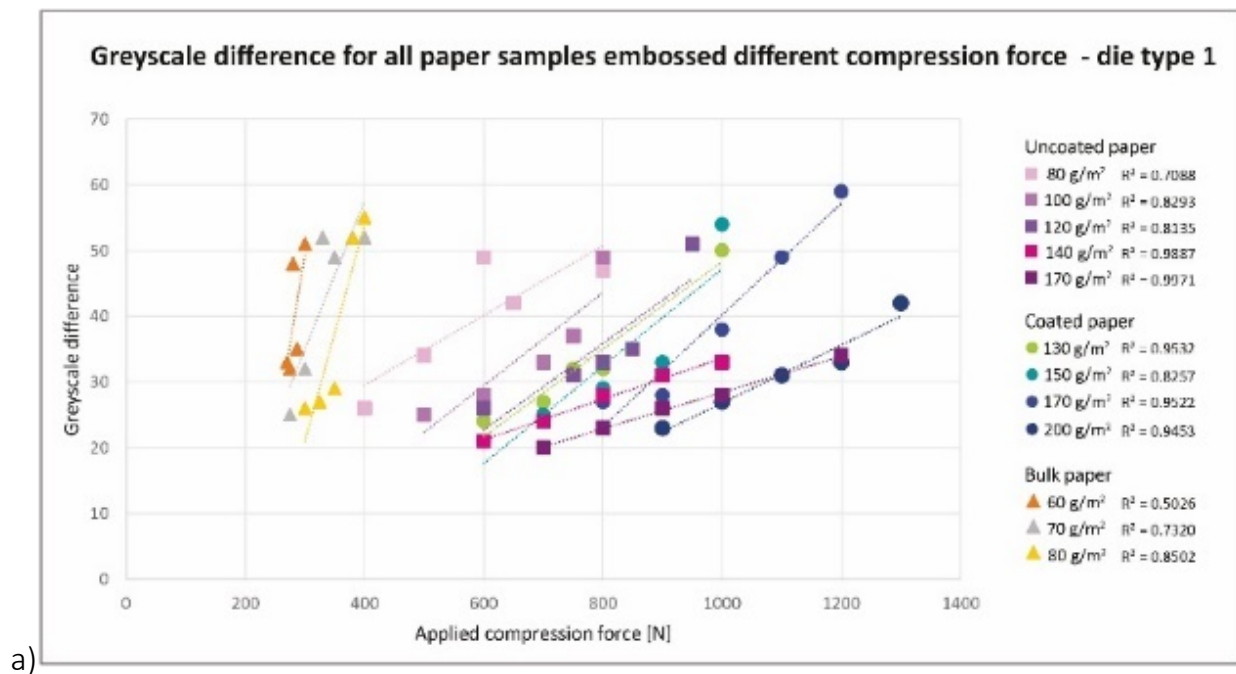

a)

Greyscale difference for all paper samples embossed different compression force - die type 2

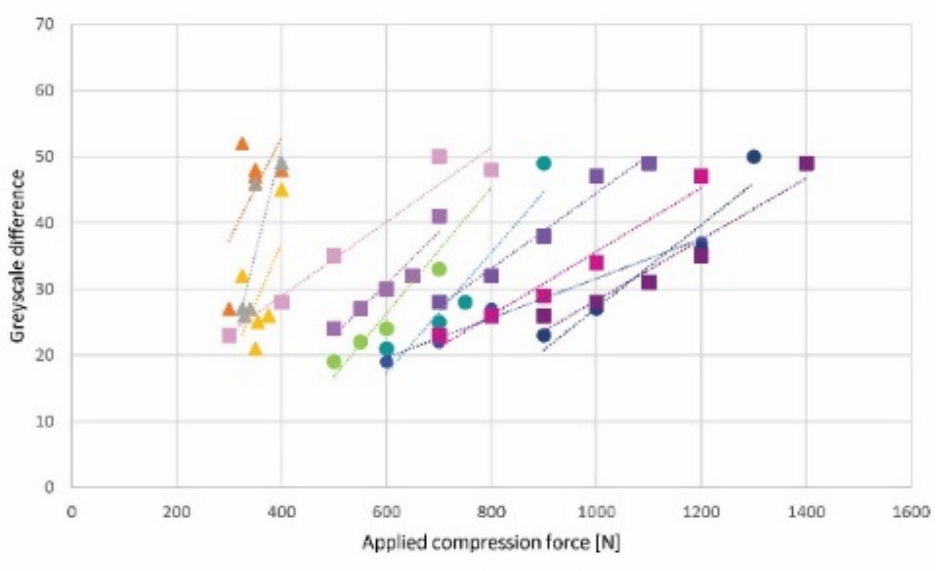

Uncoated paper

$80 \mathrm{~g} / \mathrm{m}^{2} \quad \mathrm{R}^{2}=0.9465$

$100 \mathrm{~g} / \mathrm{m}^{2} \mathrm{R}^{2}-0.9119$

$120 \mathrm{~g} / \mathrm{m}^{2} \mathrm{R}^{2}=0.9704$

$140 \mathrm{~g} / \mathrm{m}^{2} \mathrm{R}^{2}=0.9654$

- $170 \mathrm{~g} / \mathrm{m}^{2} \mathrm{R}^{2}-0.9387$

Coated paper

- $130 \mathrm{~g} / \mathrm{m}^{2} \mathrm{R}^{2}-0.9538$

- $150 \mathrm{~g} / \mathrm{m}^{2} \mathrm{R}^{2}=0.0410$

- $170 \mathrm{~g} / \mathrm{m}^{\prime} \mathrm{R}^{2}-0.9834$

$200 \mathrm{~g} / \mathrm{m}^{\prime} \mathrm{R}^{\mathrm{r}}-0.9078$

Bulk paper

$\Delta 60 \mathrm{~g} / \mathrm{m}^{2} \mathrm{R}^{2}-0.3420$

$\Delta 0 \mathrm{~g} / \mathrm{m}^{2} \quad \mathrm{R}^{t}=0.7067$

$\Delta 80 \mathrm{~g} / \mathrm{m}^{2} \quad \mathrm{R}^{2}=0.3088$

b)

Greyscale difference for all paper samples embossed different compression force - die type 3

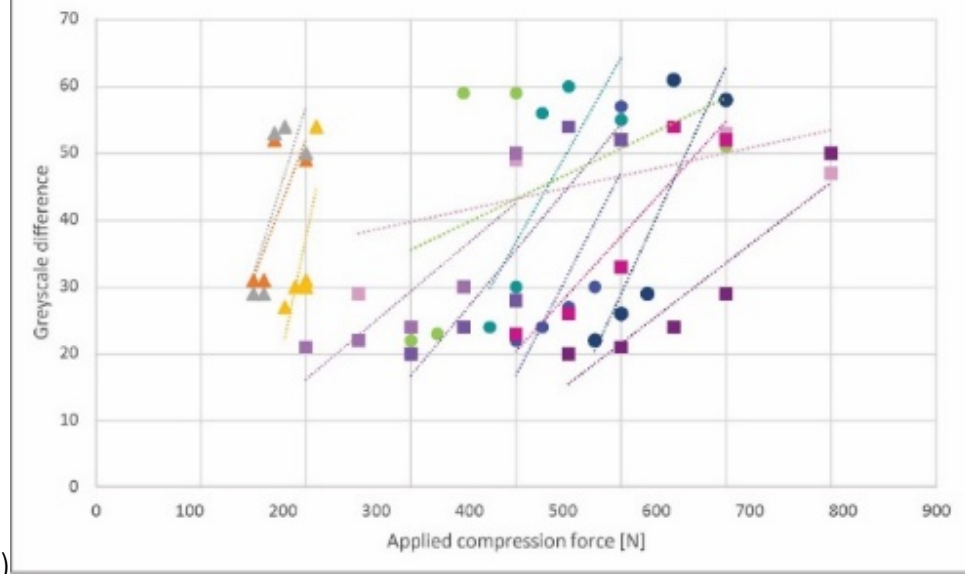

Uncoated paper

$=80 \mathrm{~g} / \mathrm{m}^{2} \quad \mathbf{R}^{2}=0.4145$

$=100 \mathrm{~g} / \mathrm{m}^{2} \mathrm{R}^{2}=0.7522$

= $120 \mathrm{~g} / \mathrm{m}^{2} \quad \mathrm{R}^{2}=0.8470$

$140 \mathrm{~g} / \mathrm{m}^{2} \mathrm{k}^{2}=0.875$

$170 \mathrm{~g} / \mathrm{m}^{2} \mathrm{R}^{2}=0.8802$

Coated paper

- $130 \mathrm{~g} / \mathrm{m}^{2} \mathrm{~F}^{2}-0.2351$

- $150 \mathrm{~g} / \mathrm{m}^{2} \mathrm{k}^{2}=0.6322$

- $170 \mathrm{~g} / \mathrm{m}^{2} \mathrm{R}^{2}=0.706$

- $200 \mathrm{~g} / \mathrm{m}^{2} \mathrm{R}^{2}-0.7623$

Bulk paper

$\triangle 60 \mathrm{~g} / \mathrm{m}^{2} \quad \mathrm{R}^{2}-0.5600$

$\triangle 70 \mathrm{~g} / \mathrm{m}^{2} \quad \mathrm{R}^{2}=0.5589$

$80 \mathrm{~g} / \mathrm{m}^{2} \quad \mathrm{R}^{2}=0.5918$

c)

Figure 6 (part 1): Greyscale difference for all paper samples embossed with different compression forces and die type 1 (a), 2 (b), 3 (c) and 4 (c) 


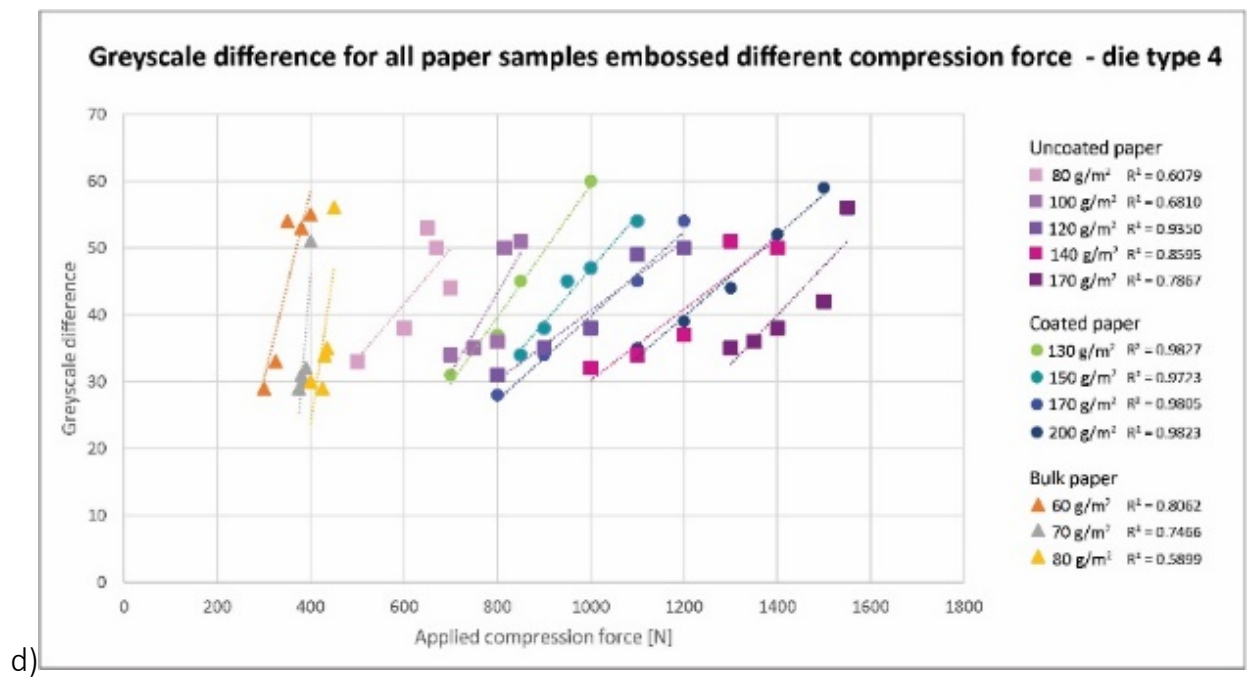

Figure 6 (part 2): Greyscale difference for all paper samples embossed with different compression forces and die type $1(a), 2(b), 3(c)$ and 4 (c)

After the optimal compression force selection, the repeatability test took place and the obtained results are presented in Figure 7.

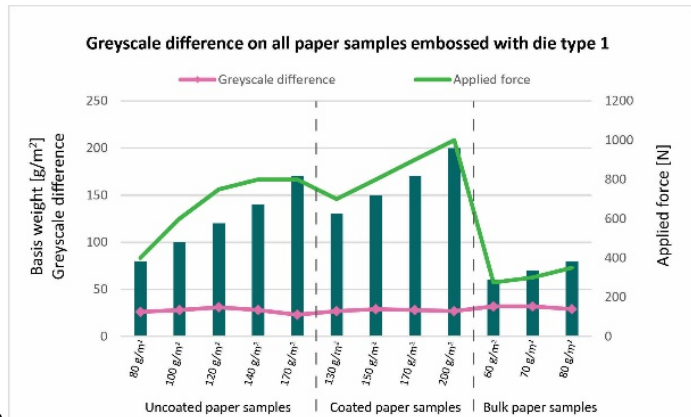

a)

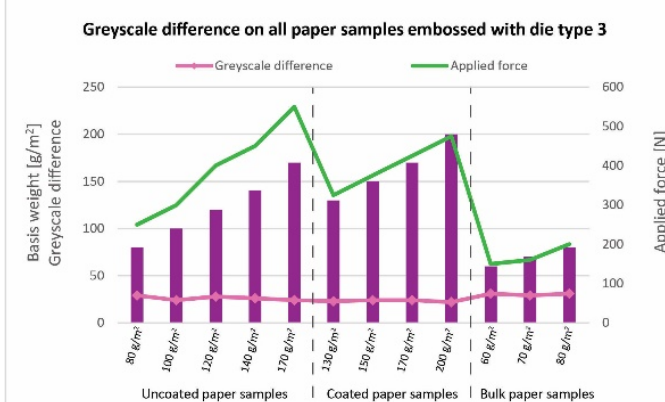

c)

Figure 7: Greyscale difference for all paper samples embossed with the previously selected optimal compression force and embossing die type 1 (a), 2 (b), 3 (c) and 4 (c)

At first sight, the presented graphs look very similar, suggesting a certain level of homogeneity among the obtained results, however there are some differences. The similarities among the obtained results are primarily related to the values for optimal compression forces and shadow-based contrast values in general. Based on the presented graphs, it can be noticed, that the optimal compression forces (selected in previous step for every paper grade and basis weight individually) had increasing tendency with the basis weight increasement. Papers with lower basis weight needed lower compression forces to form sufficiently visible embossed image without damages, while for the papers with higher basis weight the compression forces were also higher. This tendency was identical for all paper grade or embossing die. The other 
similarity between the presented graphs is the uniform structure of the obtained values of greyscale level difference for each embossing die individually, but at the same time, these results gave the first difference among the presented diagrams. Namely, three of four embossing dies derived greyscale level differences in very close range (die 1: from 23 to 32; die 2: from 24 to 31; die 3: from 22 to 31), while for embossing die type 4, slightly higher values were observed (from 29 to 39). This fourth embossing die had a larger geometric element in negative image, which could have caused more emphasized shadow areas on the scanned images, thus higher values of shadow-based contrast. The second difference between the derived results was regarding to paper grade. Namely, the uncoated papers needed the highest compression forces in 3 out of 4 cases to provide the adequate visibility without damages (800N, 1100N, 550N and 1350N for the embossing dies 1, 2, 3 and 4, respectively). The coated papers required slightly lower values (1000N, $1000 \mathrm{~N}, 475 \mathrm{~N}$ and $1200 \mathrm{~N}$ ) except the 1. die, while the bulk papers were embossed with significantly lower values regardless of the used die $(350 \mathrm{~N}, 375 \mathrm{~N}, 200 \mathrm{~N}$ and $430 \mathrm{~N})$. The possible explanation for these variations in compression forces lies in the structural and surface properties, as well as the overall strength of the selected papers.

\section{CONCLUSIONS}

In this paper, the applicability of a simple flatbed scanner and an image processing algorithm for embossing quality evaluation have been analysed and presented. The main focus was given to the embossing pressure analysis, based on the difference between the average grayscale levels of areas under and outside shadows on the previously scanned embossed substrates. After a detailed visual assessment of all scanned paper samples and analysis of the obtained results, it can be stated that a simple flatbed scanner, as an acquisition equipment, can realistically digitalized the embossed paper samples (at least the single-level embossed images). Additionally, although, there were some low values of coefficients of determination, the presented results are indicating strong correlation between the shadow-based contrast value and the applied compression force, i.e. the initial hypothesis was correct: it is possible to track changes in the values of shadow-based contrast in accordance to the applied compression force. Regarding the paper grade, basis weight and type of test elements on the embossing dies, the obtained results imply that the proposed image feature, the shadow-based contrast has a potential to be used in embossing quality evaluation as an objective measure not only for deformation rate tracking, but also as a reference parameter to ensure adequate visibility of embossed elements by defining the minimum value of needed contrast.

\section{ACKNOWLEDGMENTS}

This research(paper) has been supported by the Ministry of Education, Science and Technological Development through the project no. 451-03-68/2020-14/200156: "Innovative scientific and artistic research from the FTS (activity) domain".

\section{REFERENCES}

[1] Banjanin, B., Vladić, G., Pál, M., Dimovski, V., Adamović, S., Bošnjaković, G.: "Production factors influencing mechanical and physical properties of FDM printed embossing dies", Proceedings of the 9th International Symposium on Graphic Engineering and Design GRID 2018, (University of Novi Sad, Faculty of technical sciences, Department of graphic engineering and design, Novi Sad, 2018), pages 225-236.

[2] Blechschmidt, J.: "Papierverarbeitungstechnik", (Hanser Verlag, München, 2013.).

[3] Bošnjaković, G., Vladić, G., Pál, M., Banjanin, B., Dedijer, S.: "Performance evaluation of paper embossing tools produced by fused deposition modelling additive manufacturing technology", Journal of Graphic Engineering and Design 8 (2), 47-54, 2017. doi: 10.24867/JGED-2017-2-047.

[4] Canon: "Instruction Manual for Canon CanoScan 5600F", URL: https://www.canon.rs/scanners/flatbed-scanners/canoscan_5600f/ (last request: 2020-08-09).

[5] Drobchenko, A., Kamarainen, J-K., Lensu, L., Vartiainen, J., Kälviäinen, H., Eerola, T.: "Thresholdingbased detection of fine and sparse details", Frontiers of Electrical and Electronic Engineering in China 6 (2), 328-338, 2011. doi: 10.1007/s11460-011-0139-x. 
[6] Fedrigoni: "Technical data Symbol Freelife Satin", URL:

ttps://www.fedrigonipapers.com/sites/default/files/2019-12/Symbol\%20Freelife\%20Satin_1.pdf (last request: 2020-08-06).

[7] FSEA: "Embossing and Foil Stamping Techniques Made Easy Reference Guide", URL: https://www.fsea.com/content/design/designer-guidebook.shtml (last request: 2020-07-16).

[8] Goncalves, N., Carvalho, V., Belsley, M., Vasconcelos, R.M., Soares, F.O., Machado, J.: "Yarn features extraction using image processing and computer vision - A study with cotton and polyester yarns", Measurement 68, 1-15, 2015. doi: 10.1016/j.measurement.2015.02.010.

[9] Hellefoss: "Technical data Hellefos Snowbulk 70 ISO" URL: https://www.hellefoss.com/files/Product_assortment_Snowbulk_70_ISO.pdf (last request: 2020-08-06).

[10] Holik, H.: "Handbook of paper and board", (Wiley-VCH Verlag, Weinheim, 2013.).

[11] Iggesund: "Reference manual", URL: https://www.iggesund.com/services/our-services/downloadcentre/\#id10162_Knowledge (last request: 2020-07-05).

[12] Inspectron: "Gold Embossing", URL: https://www.inspectron.com/goldembossing\# (last request: 2020-07-10).

[13] Kluge: "The Designers Guide to Foil Stamping Embossing", URL: https://www.kluge.biz/wpcontent/uploads/2015/10/Embossing-and-Foil-Stamping-Techniques-Made-Easy-ReferenceGuide.pdf (last request: 2020-07-16).

[14] Malek, A. S.: "Online fabric inspection by image processing technology", Ph.D. thesis, University of Haute Alsace, 2012.

[15] Mondigroup: "Technical data Maestro Print", URL: https://igepa.hr/media/1271/maestro-print.pdf (last request: 2020-08-06).

[16] Nashat, S., Abdullah, A., Abdullah, M. Z.: "Machine vision for crack inspection of biscuits featuring pyramid detection scheme", Journal of Food Engineering 120 (1), 233-247, 2014. doi: 10.1016/j.jfoodeng.2013.08.006.

[17] Peret, Application Note Embossing Depth CREASY Software Version v5.x, peret, URL: http://www.peret.it/PDF/Manual/CREASY\%20EGUIDEPRO\%20Embossing\%20Application\%20Note.pdf (last request: 2020-07-18).

[18] Peret, EGUIDE-PRO Embossing Test Patch, URL: http://www.peret.it/Articles/Embossing\%20Test\%20Patch.pdf (last request: 2020-07-18).

[19] SAPPI: "Standard 5: Tip 5 - Embossing", URL: https://www.sappi.com/standard-5-tip-5-embossing (last request: 2020-07-10).

[20] Shimadzu Corporation, Shimadzu Compact Tabletop Testing Machine EZ test EZ-LX/EZ-SX Series Instruction Manual, Shimadzu, URL:

https://www.ssi.shimadzu.com/sites/ssi.shimadzu.com/files/Products/literature/testing/C224E055c.pdf (last request: 2020-08-11).

[21] Sinha, S. K. "Automated underground pipe inspection using a unified image processing and artificial intelligence methodology", Ph.D. thesis, University of Waterloo, 2000.

[22] Starrett, Embossing Depth Measurement for Profile Extrusion Processes, Starrett, URL: https://www.starrett.com/docs/other-downloadable-resources/embossing-depth-measurement--bulletin-3004.pdf?sfvrsn=5 (last request: 2020-07-15).

[23] Storaenso: "Paperboard Guide 2019", URL: https://info.storaenso.com/signup-paperboardguide?cc-option-checkbox=Essential (last request: 2020-07-10).

[24] Terrill, A.: "Embossing vs Debossing: An In-depth Guide", URL: https://www.printpeppermint.com/embossing-vs-debossing-an-in-depth-guide/ (last request: 2020-08-05).

[25] Topac, Technical information on embossing/debossing, Topac, URL: https://www.topac.de/fileadmin/content/c_Leistungen/Embossing_Debossing.pdf (last request: 2020-07-25).

[26] Žarko, J., Vladić, G., Pál, M., Dedijer, S.: "Influence of printing speed on production of embossing tools using FD M 3D printing technology", Journal of Graphic Engineering and Design 8 (1), 19-27, 2017. doi: 10.24867/JGED-2017-1-019. 


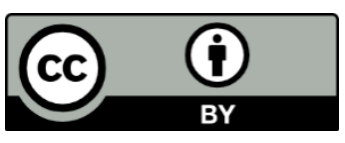

(C) 2020 Authors. Published by the University of Novi Sad, Faculty of Technical Sciences, Department of Graphic Engineering and Design. This article is an open access article distributed under the terms and conditions of the Creative Commons Attribution license 3.0 Serbia

(http://creativecommons.org/licenses/by/3.0/rs/). 